\title{
CADUCIDAD DEL TÍTULO EXTRANJERO Y PRESCRIPCIÓN DE LA ACCIÓN EN MATERIA DE OBLIGACIÓN DE ALIMENTOS. COMENTARIO AL AAP DE LÉRIDA (SECCIÓN 2) NÚM. 203/2020 DE 13 OCTUBRE 2020
}

\author{
PRESCRIPTION OF THE THE RIGHT TO ENFORCE A DECISION \\ AND EXPIRY OF THE RIGHT OF ACTION IN MATTERS \\ RELATING TO MAINTENANCE OBLIGATIONS. PURPOSE TO \\ THE JUDGEMENT OF THE COURT OF APPEAL OF LERIDA \\ NUMBER 203/2020 OF 13TH OCTOBER
}

\author{
Luis F. Carrillo Pozo \\ Profesor de Derecho internacional privado \\ Universidad de Almería \\ ORCID: 0000-0002-5507-167X
}

Recibido: 03.06.2021 / Aceptado:21.06.2021

DOI: https://doi.org/10.20318/cdt.2021.6284

Resumen: El auto de la AP de Lérida de 13 de octubre de 2020 ilustra los problemas de interpretación del art. 21.2 del reglamento 4/2009, que prescinde de la lex causae en cuanto a subsistencia del derecho a recibir alimentos para dar cabida en la fase de ejecución a la posible aplicación de otros ordenamientos. El presente comentario trata de poner de manifiesto las dificultades de puesta en funcionamiento de la norma.

Palabras clave: alimentos, caducidad del título ejecutivo, prescripción.

Abstract: The order of the AP of Lérida of October 13, 2020 illustrates the problems of interpretation of art. 21.2 of regulation 4/2009, which dispenses with the lex causae in terms of subsistence of the right to receive alimony payments in order to accommodate the possible application of other legal systems in the enforcement stage. This comment attemps to highlight the difficulties of implementation of the rule.

Keywords: maintenance, expiry of the right of action, prescription of the right to enforce a decision.

Sumario: I. Los datos del litigio. II. La caducidad del título ejecutivo y la prescripción del derecho: Las normas en presencia. III. Elementos para la duda (memorial para escépticos). IV. Conclusión resignada.

1. Es harto frecuente, cuando se habla de alimentos, expresar el desconcierto que produce la concurrencia de fuentes de regulación, que genera un verdadero empacho ${ }^{1}$. Aun siendo un problema

\footnotetext{
${ }^{1}$ Recientemente ponía de relieve F. Garau Sobrino cómo para un caso sustancialmente idéntico el operador puede verse en la tesitura de tener que deslindar entre seis, sean convenios, reglamentos o ley interna: "El laberíntico sistema español de reconocimiento y ejecución de resoluciones extranjeras", en P. Domínguez Lozano (ed.), Derecho internacional privado europeo.
} 
de envergadura, no es a mi juicio la más grave de las dificultades que en este tema se suscitan: Al fin y al cabo, bastará refrescar los rudimentos de Derecho internacional público para individualizar el texto aplicable, e incluso en caso de error los tribunales hacen el trabajo de los letrados (art. 218.1 inciso segundo de la $\mathrm{LEC}^{2}$ ). Lo malo viene cuando, instalados en el reglamento 4/2009 de forma indubitada, nos topamos con normas que (al menos a mi entender) no encajan en la filosofía y espíritu de un texto sobre esta materia. Su art. 21.2 encierra un compromiso cuyas soluciones tocan tanto a lo procesal como a lo sustantivo, en la medida en que tiene que partir de la base -como no puede ser de otro modo- de la regla sobre sujeción a la lex fori del desarrollo del proceso de ejecución (y eso incluye la norma sobre caducidad del título), pero acoge una extraña fórmula de suspensión o denegación de la ejecución cuando el derecho a reclamarlos haya prescrito o bien de acuerdo con esta misma ley del foro o bien conforme a la del Estado de origen, entendidas ambas en el sentido más extenso. Esa inesperada norma se convierte en la clave esencial de la resolución que paso a comentar.

\section{Los datos del litigio}

2. Tal vez sea un poco farragosa la sucesión de fechas que jalonan la historia, pero, hablando de caducidad y prescripción, cuento de antemano con la benevolencia del lector.

En el origen del auto comentado se halla la sentencia de la sección de familia y menores del tribunal de distrito de Chrzaniwie (Polonia), de 24 de mayo de 2012, que condenaba al pago de alimentos en favor de un residente en Polonia a un ciudadano del que se sabe que ahora vive en España ${ }^{3}$. En lugar de solicitar la ejecución directa, se acude a la vía de la cooperación entre autoridades centrales (art. 55) cursada mediante escrito del abogado del Estado de 10 de julio de 2015, completado (poder, cuenta de la deuda) el 26 de noviembre siguiente. Parece ser que en abril de 2016 se formuló una reclamación extrajudicial, pero esto no queda acreditado documentalmente en el momento procesal oportuno: Valga al menos para fundar la sospecha de que los incumplimientos vienen de antiguo.

La demanda solicitando el despacho de ejecución es de 19 de abril de 2018. Se formula oposición por parte del ejecutado y del ministerio fiscal, alegando la caducidad del título, ex art. 518 LEC. El juez de primera instancia no la estima, pero aplica en su lugar el art. 121-21 CC de Cataluña (prescripción trienal), ordenando, por auto de 20 de noviembre de 2018, que prosiga la ejecución, por las cantidades devengadas a partir de 19 de abril de $2015^{5}$. La abogacía del Estado recurre en apelación, acudiendo a argumentos a veces sensatos (no se trata de un declarativo, sino de la ejecución de un título extranjero, por lo que no procedería aplicar la mencionada norma del CC de Cataluña sino la LEC, lo que retrotraería la fecha a partir de la cual se puede reclamar la deuda a la del mismo momento del dictado de la sentencia), a veces sorprendentes (el requerimiento extrajudicial de 2016 suspendió el plazo caducidad del título) ${ }^{6}$.

Diálogos con la práctica, Valencia, 2020, p. 128 en particular. Añádase las posibilidades de modalización ofrecidas por algunos convenios vía reservas, declaraciones y facultades de desconexión y el cuadro quedará completo: A. Borrás RodríguEz, "The Necessary Flexibility in the Application of the New Instruments on Maintenance", en K. Boele-woelki y otros (eds.), Convergence and Divergence in Private International Law. Liber amicorum Kurt Siehr, Zurich, 2010, pp. 180 ss.

${ }^{2}$ El acreedor no puede quedar perjudicado: chocaría con la filosofía subyacente. En este sector el TS establece que en caso de silencio en la invocación de instrumentos el órgano judicial debe acudir a aquel que en mayor medida favorezca la concesión del exequatur (allí donde sea necesario): AATS 30 enero 1996, 6 junio 2000, 9 julio 2002, 17 mayo 2005. Por esa misma lógica, podemos entender que, si se solicita sólo el exequatur cuando lo que corresponde es pedir el despacho de ejecución (si se pide ambas cosas no ha lugar a discusión alguna), se puede otorgar ésta, ya que -además- quien puede pedir lo más está pidiendo implícitamente lo menos.

${ }^{3}$ El importe de la pensión quedó establecido en 1000 zlotys, que al cambio serían unos 220 euros. Reténgase el dato por lo que se verá infra.

${ }^{4}$ Recuérdese que existen dos vías alternativas. No es obligatorio recurrir a la asistencia de la autoridad central del Estado de ejecución, pudiéndose instar la ejecución de forma directa: STJ 9 febrero 2017 (asunto C-283/16), MS c. PS.

5 Artículo 121-21. Prescripción trienal. Prescriben a los tres años:

a) Las pretensiones relativas a pagos periódicos que deban efectuarse por años o plazos más breves.

(...)

${ }^{6}$ Los pedimentos subsidiarios son todo menos un ejercicio de coherencia: Se solicitaba que, si se rechazaba la eficacia interruptiva de la caducidad del requerimiento, al menos se aplicara el art. 518 LEC y se condenara a pagar las pensiones devenga- 
3. La respuesta del tribunal peca tal vez de exceso. Es casi una constante en los operadores -inseguros en el maremágnum del Derecho internacional privado, enfrascados en un razonamiento que con frecuencia se les antoja un arcano- la acumulación de datos, normas y argumentos, vengan o no a cuento. Aquí, por ejemplo, comparecen extremos como el art. 15 del reglamento 4/2009 (como si se discutiera sobre ley aplicable al fondo del asunto) o desarrollos sobre ejecución de decisiones al amparo del extinto reglamento Bruselas I, sin perjuicio de la doctrina jurisprudencial emanada a propósito de la prescripción de las obligaciones de pago periódico en el Derecho catalán. En lo que nos interesa, la argumentación del auto de la Audiencia leridana puede ser resumida en las siguientes proposiciones: a) No se acepta la tesis del recurrente cuando defiende que únicamente resulta aplicable el art. 518 LEC, siéndolo también el de prescripción previsto en el art. 121-21 CC de Cataluña (FJ $\left.4^{\circ}\right)$; b) Pero la normativa relevante sobre prescripción no es la del CC catalán sino la del Estado miembro de ejecución, o sea, el art. 1966.1 CC, cinco años (FJ 5 ${ }^{\circ}$ ); c) Para saber si la acción de ejecución de una resolución dictada por otro Estado miembro ha sido ejercitada a tiempo hay que estar a la fecha de entrada en el Ministerio de Justicia de la solicitud de cooperación (2015); d) Y ello porque el solicitante no puede verse perjudicado por la realización de los trámites intermedios hasta la interposición de la demanda de ejecución o por las dilaciones que no le son imputables; e) En consecuencia, la acción no ha prescrito y procede ordenar la continuación de la ejecución despachada, imponiendo las costas de la primera instancia al ejecutado.

A partir de ahí quiero centrar las páginas que siguen a tratar de la caducidad del título, la relación entre caducidad y prescripción del derecho y las dificultades de comprensión y puesta en funcionamiento del mencionado art. 21 del reglamento 4/2009.

\section{La caducidad del título ejecutivo y la prescripción del derecho: Las normas en presencia.}

4. Va de suyo que sólo se pueden ejecutar títulos dotados de ejecutividad conforme a la ley del Estado cuyos tribunales los hayan emanado. Es la expresión del control y soberanía del Derecho del Estado de origen, cuya consecuencia es la acogida del modelo de extensión de los efectos en sede de reconocimiento y ejecución ${ }^{7}$. Pero una vez entran en el espacio jurídico del foro se equiparan -en todo- a las decisiones locales. Por eso tiene sentido que el TJ haya incluido la fijación de un plazo de caducidad de los títulos entre las vicisitudes atinentes a la ejecución, materia no unificada y por lo tanto disciplinada por cada Estado de forma autónoma, que decide libremente ${ }^{8}, 9$. Y tiene sentido igualmente que el propio

das desde cinco años antes de la demanda (mayo de 2013); subsidiariamente se defendía que en caso de aplicar las normas sobre prescripción se admitiera que el plazo se interrumpió con la reclamación de 2016, condenando al pago desde mayo de 2013.

Por lo demás, el MF se adhiere al recurso (lo que se llama continuidad de los planteamientos); el ejecutado no comparece en esta segunda instancia.

7 Recuérdese que, como es sabido, el modelo de extensión de los efectos no aparece expresamente en ningún texto normativo, pero ha sido reconocida por el TJ en sentencias de 4 de febrero de 1988 (Hoffmann, par. 11), 28 de abril de 2009 (Apostolides, par. 66), 13 de octubre de 2011 (Prism investments, par. 39) y 15 de noviembre de 2012 (Gothaer, par. 34).

8 Afirma en la sentencia de 4 octubre 2018 (asunto C 379/17) que «...la ejecución propiamente dicha (...) sigue sometida al Derecho nacional del juez que conoce de ella, sin que la aplicación de las normas procesales del Estado miembro requerido en el marco de la ejecución pueda menoscabar la eficacia del régimen previsto por dicho Reglamento [se refiere a Bruselas I] en materia de exequatur limitando la operatividad de los principios impuestos en la materia, de manera expresa o tácita, por el propio Reglamento».

Ya antes el TS español lo había dejado claro en su única resolución -salvo error por mi parte- que se ha pronunciado sobre el tema: «La solicitud de ejecución de la resolución dictada por un Estado miembro, al amparo del Reglamento (CE) 44/2001, no tiene un plazo de prescripción o de caducidad propio, sino que ha de aplicársele el previsto para la ejecución de los títulos judiciales. Dado que Reglamento comunitario no regula el plazo en que ha de pedirse la ejecución de la resolución del Estado miembro en otro, a falta de tal previsión expresa ha de aplicarse subsidiariamente la lex fori» (sentencia de 16 octubre 2014).

9 Recuérdese, en este sentido, que los plazos de ejecución de los títulos judiciales oscilan considerablemente, desde los 5 años previstos en la LEC, hasta 30 en Alemania (§ 197.1.3. BGB), pasando por los 10 de Francia (art. L 111-4 CPC). A los efectos de la debida comprensión de la norma controvertida, téngase presente que la noción de caducidad del título no existe en los sistemas comparados, prefiriéndose hablar de prescripción del derecho a la ejecución del título, como cualquier otro derecho; es como si, una vez se incorpora al título, el derecho subjetivo cambiara de naturaleza, hasta el punto de que se alteran los plazos en los que puede ser hecho efectivo, que ya no son los del objeto litigioso sino los de la resolución (en un sentido parecido se manifiesta el AAP de Asturias de 17 septiembre 2007, que habla de sustitución de plazos). 
TJ haga una lectura amplia del concepto de ejecución hasta extender la competencia del juez encargado de ella a las vicisitudes que de un modo u otro se le vinculen, y siempre con el límite máximo de no poder alterar el contenido de lo decidido (sentencia de 4 junio 2020) ${ }^{10}$. Al igualar las resoluciones dictadas en el foro y las de tribunales extranjeros se potencia la seguridad y el ahorro mediante la estandardización del procedimiento ejecutivo ${ }^{11}$. Estas orientaciones siempre han quedado claras en los reglamentos: Por citar sólo tres ejemplos, es lo que sancionan el art. 41 del reglamento 1215/2012, el art. 23 del 655/2014 o el art. 51 del 2019/1111, y en el ámbito interno el art. 50.2 LCJI. En consecuencia, no es exótico que el art. 41 del 4/2009 asevere que «A reserva de lo dispuesto en el presente Reglamento, el procedimiento de ejecución de las resoluciones dictadas en otro Estado miembro se regirá por el Derecho del Estado miembro de ejecución. Las resoluciones dictadas en un Estado miembro que tengan fuerza ejecutiva en el Estado miembro de ejecución serán ejecutadas en este en las mismas condiciones que si se hubieran dictado en dicho Estado miembro de ejecución». El alcance de ese "a reserva" mencionado al principio de la disposición no puede ser tal que adultere el régimen extendido hasta el extremo de contradecir la regla general, y fundamentalmente no es concebible ni que un legislador racional rompa la paridad de decisiones en el foro ni que en la fase de ejecución se puedan discutir elementos de fondo.

5. Permítaseme recordar unas cuantas obviedades más. Nunca se ha dudado de que una cosa es el título que abre la ejecución y otra el alcance de las prestaciones que se pueden reclamar. Aquello es un tema procesal (soberanía de la lex fori), esto es cuestión de fondo cubierta -y resuelta- por la lex causae. Pero lo primero es saber si existe o no un título ejecutivo de acuerdo al sistema procesal del juez de la ejecución, en la medida en que sólo si efectivamente existe se puede pasar a la siguiente pregunta, la de su eficacia en el tiempo. Por supuesto que, como todo elemento relativo a la subsistencia del título, la fijación del dies a quo para determinar si está vigente o no, compete a la LEC, al tratarse de procedimientos que se desenvuelven en España. Los problemas en materia de alimentos se suscitan cuando se demanda para conseguir una condena con alcance retroactivo o cuando se reclaman atrasos, y es ahí donde confluyen esos dos ordenamientos, porque la ley del foro establecerá un tope máximo en la fase de ejecución: Si, por ejemplo, en 2010 se interpone una demanda, el Derecho regulador de la prestación dirá si se pueden conceder desde 2007, 2005 o desde la fecha que sea; pero, si cuando se solicite su ejecución en España, el plazo que cuenta es el de cinco años del art. 518 LEC, tal y como ha sido interpretado por la jurisprudencia, matizando el rigor de esta disposición respecto a condenas al pago de prestaciones periódicas o prestaciones futuras cuyo incumplimiento es incierto, para fijar aquel en el día del último incumplimiento ${ }^{12}$. El reparto de funciones es, pues, claro, con dos delimitaciones temporales ${ }^{13}$ : La lex causae marca el máximo reclamable -y reconocible- en un declarativo, la lex fori

\footnotetext{
${ }^{10}$ Esta sentencia (asunto C 41/19) contiene dos párrafos con aseveraciones cruciales para lo que nos interesa en este breve comentario: Del art. 41 del Reglamento 4/2009 se desprende que el conocimiento de una demanda que tenga un vínculo estrecho con el procedimiento de ejecución de una resolución dictada por un órgano jurisdiccional del Estado miembro de origen y mediante la que se haya declarado la existencia de un crédito de alimentos es, al igual que el conocimiento de la propia demanda de ejecución de dicha resolución, competencia de los órganos jurisdiccionales del Estado miembro de ejecución (38); un motivo de oposición alegado por el deudor ante el órgano jurisdiccional del Estado miembro de ejecución no pretende modificar esa resolución o que se adopte una nueva en este último Estado miembro, ni solicitar la revisión en cuanto al fondo de dicha resolución en ese Estado (46). Leído en clave interesada: No lo pretende porque es impensable que lo pretenda.

${ }^{11}$ Se lee en la misma sentencia que «la autoridad alemana encargada de la llevanza del Registro de la Propiedad no puede determinar si el Derecho del Estado miembro en el que se dictó el mandamiento de embargo preventivo establece un plazo de ejecución ni las modalidades de dicha ejecución, al igual que no está autorizada para aplicar una norma del Derecho de ese Estado miembro».

${ }^{12}$ La fecha del incumplimiento de los pronunciamientos es el momento en el que nace el derecho del interesado para solicitar su cumplimiento y, por tanto, para instar la ejecución, como señala el AAP de Cáceres de 23 enero 2020, por citar un ejemplo reciente entre cientos. Recomendable también el AAP de Ávila de 25 julio 2019, poniendo el acento en la imposibilidad de ejercitar la acción ejecutiva mientras no se incumpla.

Por eso en esta sede internacional privatista es crucial no sólo conocer la fecha de la resolución sino también acreditar que ha habido incumplimientos y a partir de cuándo. Sólo si se ha marcado la casilla del punto 5.2.1.4 de los anexos I y III (los relevantes en este caso controvertido) ha lugar a esta ulterior prueba (art. 20.1.c del reglamento 4/2009); para pagos únicos o prorrateados (5.2.1.2 y 5.2.1.3) bastará el formulario.

${ }_{13}$ Con la consecuencia de que por mucho que en la resolución extranjera se haya reconocido el derecho a cobrar alimentos
} 
acota lo que en ese momento se puede pedir en concreto. Es diáfano que no es posible dar más de lo que en el título se haya concedido ${ }^{14}$.

6. Sobre este trasfondo irrumpe el mentado art. 21.2 del reglamento 4/2009: «A instancia del deudor, la autoridad competente del Estado miembro de ejecución denegará la ejecución total o parcial de la resolución del órgano jurisdiccional de origen cuando el derecho a obtener la ejecución de dicha resolución haya prescrito ya sea en virtud del Derecho del Estado miembro de origen o en virtud del Derecho del Estado miembro de ejecución, si este estableciera un plazo de prescripción más largo» ${ }^{15}$. ¿De qué habla esta norma? En una primera aproximación se podría dudar sobre si es una norma especial sobre caducidad del título ejecutivo o si se trata de indagar directamente en la disciplina del derecho subyacente. Hablar sobre la prescripción del derecho a ejecutar una resolución conecta de algún modo con aquello (porque evoca la ejecución), pero no deja de ser cierto que esta opción supondría romper con la posición consolidada en las normas y en la jurisprudencia europea; sería tan anómalo como dejar que la caducidad no sea controlada de oficio ${ }^{16}$, y eventualmente sometida a la ley de un ordenamiento extraño en la disciplina del proceso. Por exclusión, por ello, sólo puede estar aludiendo a las normas (sustantivas) reguladoras de la prescripción del derecho debatido ${ }^{17}$, con el problema derivado de que comporta abrir una brecha en el razonamiento conflictual (que es lo que se ha hecho en el auto comentado). Al final, resulta que la norma del art. 21.2 es un cuerpo extraño en el entramado normativo, un elemento multiplicador de la complejidad ${ }^{18}$. Detengámonos un momento en este punto, empezando desde el fondo del paisaje.

7. El legislador europeo jamás ha querido poner palos en las ruedas al objetivo de la máxima eficacia en la tutela de los sujetos necesitados de protección:

desde un periodo de, $v$. $g r$., diez años, si nada se ha reclamado, en España el título sólo permite cobrar lo correspondiente a los últimos cinco años.

${ }^{14}$ El precitado AAP de Asturias de 17 septiembre 2007 aclara que el plazo para solicitar ejecución «es distinto al que el derecho sustantivo exige para la reclamación o ejercicio de cada respectivo derecho, que por quedar agotado una vez dictada resolución firme en el pleito en el que fuera ejercitado, es sustituido por un nuevo título judicial, cuyo plazo de vigencia es el citado de los cinco años, superándose así cualquier posible divergencia».

${ }^{15}$ Que se habla de prescripción del derecho a la ejecución es claro también en las otras versiones lingüísticas de nuestro entorno: «if the right to enforce the decision of the court of origin is extinguished by the effect of prescription or the limitation of action», «le droit d'obtenir l'exécution de la décision de la juridiction d'origine est prescrit», «se il diritto di ottenere l'esecuzione della decisione dell'autorità giurisdizionale d'origine è prescritto», «wenn das Recht auf Vollstreckung der Entscheidung des Ursprungsgerichts entweder nach dem Recht des Ursprungsmitgliedstaats oder nach dem Recht des Vollstreckungsmitgliedstaats verjährt ist».

${ }^{16}$ Que el art. 556 LEC permita al ejecutado alegar prescripción o caducidad no significa que no quepa prevalentemente el control por de oficio cuando se le solicita el despacho de ejecución, art. 552.1 LEC. En su defecto, el deudor podrá oponerlas.

17 De forma tajante y explícita en este sentido M. E. CORRAO, "Il diritto internazionale privato e processuale europeo in materia di obbligazioni alimentari”, en CDT, 2011, pp. 138-139 (lo que no le impide hablar de flexibilidad y simplificación al servicio del acreedor).

${ }_{18}$ Asumo mi extrañeza por la falta de observaciones críticas a la norma. Tampoco encontraremos una explicación racional: Se acepta y basta. Entre nosotros permítaseme destacar los estupendos comentarios de S. Álvarez González, "El Reglamento 4/2009/CE sobre obligaciones alimenticias: cuestiones escogidas”, en Diario La Ley, $\mathrm{n}^{\circ} 7230,31$ de julio de 2009; M ${ }^{\mathrm{a}}$ ÁNGELES RodríGUEZ VÁzquez, "La regulación del reglamento 4/2009 en materia de obligaciones de alimentos: competencia judicial internacional, ley aplicable y reconocimiento y ejecución de sentencias", en REEI, 2010 p. 29 en particular; E. CASTELLANOS Ruz, Derecho de alimentos. Aspectos internacionales y transfronterizos, Valencia, 2017, p. 120; J. I. PARedes Pérez, "Reconocimiento y ejecución de pronunciamientos vinculados a la crisis matrimonial y modificación de resoluciones extranjeras", en M. Guzmán Zapater/M. Herranz Ballesteros, Crisis matrimoniales internacionales y sus efectos. Derecho español y de la UE. Valencia, 2018, p. 620. No deja de ser llamativo que a la norma del art. 21 a veces no se le dedica ni una sola palabra: al hablar de los medios de defensa del demandado, por ejemplo, C. PARRA RODRíGUEZ, "La obligación de alimentos para los menores: nuevas soluciones desde el derecho internacional privado”, en F. AldecoA LuZÁRraga/J. Forner I DelayguA (dirs.), La protección de los niños en el derecho internacional y en las relaciones internacionales, Madrid, 2010, p. 294; idem, "Checklist sobre el cobro internacional de alimentos: una perspectiva española", en A. BorrÁs Rodríguez/ G. GARriga SuAu, Adaptación de la legislación interna a la normativa de la Unión Europea en materia de cooperación civil. Homenaje al Prof. Ramón Viñas Farré, Madrid, 2012, p. 235; L. Sales Pallarés, "Regulación de las obligaciones de alimentos en el ámbito comunitario: el Reglamento 4/2009 y su relación con el Convenio y el Protocolo de La Haya 2007”, en F. AldeCOA LuZÁRraga/J. Forner I Delaygua (dirs.), La protección de los niños..., op. cit., p. 306. 
- En el plano conflictual, se busca simplicidad. Por eso no cabe duda de que la ley aplicable a los alimentos rige entre otras cosas el plazo de los que se puede solicitar, incluyendo los alimentos retroactivos: Al fin y al cabo, hablar de prescripción es hablar de existencia de un derecho en un momento determinado, o -dicho en negativo- de extinción de ese derecho como consecuencia de la inacción de quien está legitimado activamente para reclamar su efectividad, y eso es asunto sustantivo. Jamás se dudó de que la ley del fondo del asunto decide sobre este tema de forma incondicionada: Así aparecía en el art. 10 del Convenio de La Haya de 1973 y así consta en el art. 11 del Protocolo de 2007; en el espacio europeo tal era el tenor del art. 17 de la Propuesta de Reglamento del Consejo relativo a la competencia, la ley aplicable, el reconocimiento y la ejecución de las resoluciones y la cooperación en materia de obligaciones de alimentos de 15 de diciembre de 2005 (y por supuesto en la resolución del Parlamento Europeo de 13 de diciembre de 2007 y en los diversos trabajos preparatorios) ${ }^{19}$. Esa misma voluntad de simplificación del razonamiento en cuanto a disciplina de las obligaciones de alimentos queda igualmente acreditada -entre otras cosaspor la desaparición en el reglamento de toda norma de conflicto y su encadenamiento a la Conferencia de La Haya, y dentro del Protocolo por la plasmación (reiterada) del ámbito de aplicación de la lex causae hasta cubrir la cuestión previa del título del que depende la prestación ${ }^{20}$. Tal simplificación, no se olvide, es lo que mejor cuadra con los intereses de un acreedor de alimentos ${ }^{21}$. Pues bien, en definitiva, si esa ley -y sólo esa ley- es la que decide todo lo sustantivo, no debería tener cabida en el razonamiento ningún otro ordenamiento que de un modo u otro pueda interferir, alterar o menoscabar sus soluciones (evidentemente, el orden público como excepción se mueve en otra dimensión).

- Si pasamos al plano de la circulación de resoluciones, el objetivo prefijado desde el inicio de los trabajos que conducen al reglamento 4/2009 era suprimir el exequatur, como precipitado natural de la evolución de los sistemas procesales en un espacio judicial integrado, e imperativo fijado por el mencionado objetivo de favor creditori $^{22}$ : Rapidez y celeridad en la tutela de derechos, confianza recíproca lo exigen. De nada sirve diseñar foros de protección y aportar previsibilidad en el resultado si después las decisiones pueden ser controvertidas en la fase de ejecución ${ }^{23}$. No en vano, la historia viene de atrás: Hay un par de datos históricos coadyuvantes que vienen a remarcar la idea de máxima fluidez: a) La supresión de la causa de denegación del exequatur del art. 27.4 del Convenio de Bruselas de 1968, que permitía bucear en la ley aplicada a las cuestiones previas; b) El libro verde sobre obligaciones de alimentos denunciaba que algunos Estados a los que se les pedía el reconocimiento

19 No hace falta entrar en el tema. Con referencias a los precedentes convenios, A. BONOMI, Protocol of 23 November 2007 on the Law Applicable to Maintenance Obligations. Explanatory Report, pp. 37-38, insistiendo en la calificación sustantiva de las cuestiones temporales.

${ }^{20}$ Cfr. B. AnCEL/H. Muir Watt, “Aliments sans frontières. Le règlement CE n 4/2009 du 18 décembre 2008 relatif à la compétence, la loi applicable, la reconnaissance et l'exécution des décisions et la coopération en matière d'obligations alimentaires", en $R C D I P, 2010$, pp. 457 ss. (vid. pp. 9-10 de la edición electrónica).

${ }^{21}$ Así en la precitada sentencia del TJ de 4 junio 2020, para favorecer la concentración de competencias.

${ }^{22}$ No parece empero muy atinada la idea de que la supresión del exequatur pasa por la utilización de la misma norma de conflicto (reiterada en los trabajos de A. Borrás Rodríguez, voz más que autorizada en este tema. El más reciente, "La reclamación internacional de alimentos: De La Haya a Bruselas", en vvaA, Relaciones transfronterizas, globalización y Derecho. Homenaje el profesor doctor José Carlos Fernández Rozas, Madrid, 2020, p. 136). Lo crucial es el respeto de los derechos de las partes en el proceso, no la solución concreta alcanzada. Es absurdo otorgar a la norma de conflicto una función constitutiva de garantías en el momento de la libre circulación ( $c f r$. B. ANCEL/H. Muir WatT, "Aliments sans frontières..., op. cit.", p. 9). Por lo demás, que puede existir una circulación fluida de títulos sin unificación conflictual lo demuestra el sistema europeo (por ejemplo, el CB de 1968 o el reglamento 805/2004) y desde luego puede convivir una norma que introduzca excepciones a la libre circulación de resoluciones -como la del art. 21 del reglamento 4/2009- con la incorporación general del Protocolo de 2007: Las objeciones a esa norma no vienes desde la óptica conflictual sino desde la procesal.

En otro nivel de funcionamiento, téngase presente que alimentos es materia incluida en el ámbito de aplicación del reglamento 655/2014 (orden europea de retención de cuentas en materia civil y mercantil): Celeridad, fluidez, supresión de obstáculos interiores.

${ }^{23}$ De nuevo, B. Ancel/H. Muir WatT, “Aliments sans frontières..., op. cit.”, p. 7. 
y ejecución de una decisión sobre alimentos incoaban un nuevo procedimiento, alegando la insolvencia del deudor o el cambio de las circunstancias respectivas, dejando claro que esta práctica no encajaba en el reglamento 44/2001 en vigor en la época (al tiempo que se insistía en el rechazo de cualquier forma de revisión del fondo ${ }^{24}$ ).

8. Item más: No existen precedentes del reclamo de un ordenamiento distinto a la lex causae en la fase ejecutiva. No hay nada parecido a una causa de oposición como esta en el convenio de La Haya de 15 de abril de 1958 o en el de 2 de octubre de 1973, por definición menos cooperativos. De hecho, sus arts. 7 y 11 (respectivamente) se ordenaba que la ejecución de una resolución que condenara al pago de alimentos se concediera tanto para pagos vencidos como por vencer. Lo más similar es el convenio de La Haya sobre cobro de alimentos de 2007, cuyo art. 32.5 abre la vía de la ultraprotección del acreedor y señala que el plazo de prescripción para la ejecución de atrasos se determinará conforme a la ley del Estado de origen o la de Estado requerido, según la que establezca el plazo más largo ${ }^{25}$. Fuera de esa regla, el apartado $4^{26}$ constituye la plasmación de la primacía en la materia de la lex causae, en este caso proyectada hacia el futuro ${ }^{27}$.

Visto todo el panorama, los objetivos y los elementos de comparación ${ }^{28}$, no es fácil explicar que la prescripción del derecho a recibir alimentos apareciera configurada como causa de oposición a la ejecución en el art. 33 de la propuesta de reglamento, sin demasiadas explicaciones ${ }^{29}$.

\section{Elementos para la duda (memorial para escépticos).}

9. ¿Por qué se da entrada a una multiplicidad de leyes sustantivas en el momento de la ejecución? A falta de la más mínima explicación en los documentos oficiales, cabe intuir -sin demasiada convicción, es cierto- que todo derive del problema calificatorio: El Libro verde sobre obligaciones alimenticias alertaba de que cuando los tribunales cuyo ordenamiento califica el tema de la prescripción como procesal -los de common law- reciben una solicitud de ejecución de una decisión extranjera no eluden el control según su propio sistema de la prescripción del derecho, por más que los instrumentos internacionales lo califiquen como cuestión de fondo ${ }^{30}$. Así las cosas, visto que no parecía posible corregir esa práctica, se ha optado por extender a los ordenamientos de civil law -admítase la fórmula- la facultad de invocación y aplicación de las reglas sobre prescripción, optando por la más generosa, con voluntad de protección de los acreedores. Dicho de otra forma, si ese artículo no existiera un tribunal español no podría prestar atención a normativas sustantivas distintas a la aplicada en el título para saber si puede despachar ejecución o no de una condena a alimentos, constreñido a no salirse del contenido de la resolución extranjera y a proyectar sobre ella el art. 518 LEC.

${ }^{24}$ Libro verde sobre obligaciones alimentarias, p. 24, documento de 15 de abril de 2004. COM(2004) 254 final. Ciertamente, no se contenía sugerencia o indicación alguna sobre cuáles debían ser los motivos de denegación de la ejecución.

${ }_{25}$ Adviértase que la decisión queda en esta norma alterada mínimamente: Cuando se habla de atrasos se hace referencia exclusivamente a los alimentos no pagados, pero recogidos en la resolución. Nada se excepciona para los alimentos retroactivos (es decir, los relativos a periodos previos a la demanda), sometidos a la regla general de caducidad del título.

Se trata de una pura opción por el favor creditoris que difiere las cuestiones concretas (dies a quo, plazos, forma de cómputo) a los sistemas jurídicos nacionales: CH. A. KERN, "Haager Übereinkommen vom 23. November 2007 über die internationale Geltendmachung der Unterhaltsansprüche von Kindern und anderen Familienangehörigen, art. 33”, en T. RAUSCHER (ed.) Europäisches Zivilprozess- und Kollisionsrecht EuZPR/EuIPR, 2015, Colonia, p. 1034.

26 «Tendrán efecto todas las normas relativas a la duración de la obligación alimenticia aplicables en el Estado de origen de la decisión».

${ }^{27}$ Aunque el tenor literal de la disposición lleva a preferir la aplicación de la ley sustantiva del Estado de origen, el informe oficial anexo al convenio a cargo de A. BORRÁs y J. DEGELING evidencia que en esa fórmula deliberadamente genérica se incluyen normas sustantivas y normas de conflicto (vid. en p. 192).

${ }^{28}$ Las leyes de Derecho internacional privado que en el momento en el que se inician los trabajos eran el máximo referente (suiza, alemana e italiana) tampoco contienen previsión alguna en ese sentido.

${ }_{29}$ Posibilidad de denegación o suspensión, total o parcial, de la ejecución de una resolución judicial si el derecho a obtener la ejecución de la resolución del órgano jurisdiccional había prescrito total o parcialmente (inciso d).

${ }^{30}$ Libro verde sobre obligaciones alimentarias, presentado por la Comisión. Bruselas, 15 de abril de 2004 COM (2004) 254 final, p. 11. El compromiso de Reino unido de corregir esa práctica viene recogido asimismo en International Network of Lawyers, Le recouvrement des pensions alimentaires en Europe, s. f. p., p. 32. 
10. ¿Y cuáles son esas dudas? ¿Qué problema hay? A mi entender, es crucial la confusión de fases. Se permiten juicios extemporáneos en ejecución. ¿Desde cuándo se puede introducir alegaciones propias del declarativo en este momento? Incluso más y en general, si el modelo europeo era de control exhaustivo de las decisiones judiciales por el Estado de origen, con radical interdicción de cualquier revisión ulterior del fondo, no cabe ahora que cuestiones cuya sede natural se halla en el declarativo sean verificadas en una fase que en principio es automática.

Ahora tenemos una regla general que dice que la ejecución se somete a la lex fori y una excepción que permite tener en cuenta los datos sobre disciplina del derecho objeto de debate tal y como aparezcan regulados en sistemas algún de los cuales necesariamente no es la lex causae. Es chocante que se quiebre en un momento atípico la norma sobre ámbito de aplicación de esta ley, penetrando en ella, revisando qué es lo que dice y desplazándola en su caso ${ }^{31}$. El informe del Convenio de La Haya de 2007 abogaba, como vimos, por una comprensión amplia de la referencia al Derecho de tal o cual Estado, lo que al menos contribuye a la armonía de soluciones (en la medida en que los dos tribunales en presencia han aplicado la misma norma de conflicto y por lo tanto la misma ley); pero aquí no contamos con una indicación en ese sentido (entre otras cosas porque no existiría alternativa, al conducir a resultados idénticos, como acabamos de ver). Así las cosas, lo normal es que haya conocido el tribunal de residencia habitual del acreedor, que habrá aplicado su propia ley, mas esa coincidencia no es inexorable, de modo que el art. 21 está tolerando que sistemas jurídicos del todo ajenos a las finalidades que inspiraron el diseño de los criterios de conexión en este tema (el del juez de origen y el de la ejecución) interfieran en la asignación definitiva de alimentos. Está fuera de toda duda que con ello se hace más complejo el razonamiento ${ }^{32}$. Que esto fomente la posición de los acreedores es bastante dudoso.

11. En segundo lugar, el mecanismo de defensa sólo opera cuando los dos ordenamientos en presencia lleven a conclusiones extintivas ${ }^{33}$. La correcta puesta en funcionamiento de la norma depende por ello de la toma en consideración y comparación de los dos ordenamientos en presencia (ambos), pero para ello será necesario aportar la prueba (perfecta) de la ley extranjera. Evidentemente, se puede admitir sin ambages que el deudor que tenga interés en exonerarse del pago haciendo uso de la excepción tendrá que tomar la iniciativa, mas aquí irrumpen dos problemas ${ }^{34}$ : i) La norma habla de prescripción de un derecho, y ello exige una prueba concreta no sólo de las normas sino de las vicisitudes relativas -en particular- a inicio del plazo y formas de interrupción de la prescripción. Todo menos fácil, en definitiva ${ }^{35}$. Pues bien, la normativa de la LEC ofrece poco margen para su correcto desenvolvimiento: Se ha añadido una causa de oposición por motivos de fondo a las previstas en la ley rituaria (art. 556), y eso quiere decir que, despachada la ejecución, se concede al ejecutado un plazo de diez días para oponerse, mientras que el 560 habla de cinco días para impugnar la oposición. Pues bien, que las partes puedan proveerse de la prueba de la ley extranjera con esos plazos tan breves es realmente arduo, y tampoco las normas sobre el desarrollo de la vista en juicio verbal dan demasiado margen -ni

${ }^{31}$ Llevando al extremo la forma de operar de la norma, cabría preguntarse por qué no puede un deudor solicitar directamente la modificación de una resolución invocando su propio ordenamiento o el del Estado de origen si le resultan más beneficiosos que el aplicado, supuesto que al fin y al cabo es eso mismo lo que puede hacer en fase de ejecución. O sea: Si incumple tendrá la posibilidad de hacerlo; si no, no.

${ }^{32}$ Y no se pierda de vista que no en todos los países las ejecuciones corren a cargo de tribunales, profesionales del Derecho. Es patológico encomendar la administración de esta norma a un órgano administrativo.

${ }^{33}$ Y por supuesto en estas circunstancias se podrá volver a intentar la ejecución en otro país donde existan bienes y el plazo de prescripción no se haya extinguido: M. ANDRAe/M. Schimrick, "Verordnung (EG) Nr 4/2009 des Rates vom 18. Dezember 2008 über die Zuständigkeit, das anwendbare Recht, die Anerkennung und Vollstreckung von Entscheidungen und die Zusammenarbeit in Unterhaltssachen: Art. 21", en T. RAUSCHER (ed.) Europäisches Zivilprozess- und Kollisionsrecht EuZPR/EuIPR, 2015, Colonia, pp. 648-649.

${ }^{34}$ Cabe augurar que el resultado será que al final sólo el Derecho del foro entrará en juego como término de comparación.

35 Téngase en cuenta que en algunos sistemas el plazo se inicia el último día del año en que se haya generado el derecho (Polonia, art. 137 del Código de familia y tutela; Alemania por ejemplo, § 199 BGB, que añade el dato del conocimiento por al acreedor), en otros desde el vencimiento (art. 2224 Code civil francés), en otros el plazo se inicia con la mayor edad en caso de alimentos a menores (Portugal). Añádese a estas diferencias de matiz las complicaciones exigidas por la prueba de acontecimientos cruciales: En Chipre, por ejemplo, se excluye para el cómputo (dos años) el tiempo que el deudor hubiera permanecido fuera del territorio chipriota; en Suecia el plazo general de tres años puede verse ampliado si el deudor lo acepta. 
a los litigantes ni al tribunal- para suspender e investigarla ${ }^{36}$; ii) Como lo normal es no poder satisfacer esa exigencia, lo siguiente es saber cómo actuar en los casos en los que no se ha logrado probar el Derecho extranjero: ¿Se aplica el art. 33 LCJI? Si la respuesta es afirmativa, ¿siempre? En este caso se puede estar aplicando la ley del foro sin tener la certidumbre de que la ley del Estado de origen prevé plazos más amplios, con la consiguiente quiebra del modelo. Si se opta por un "depende", ¿cuándo y en qué condiciones? Lo que era presupuesto esencial se desvanece.

Permítaseme añadir que la ley procesal española no puede decir otra cosa distinta, no se puede flexibilizar. Lo que está mal diseñado no es el proceso civil de ejecución patrio: El defecto viene del reglamento ${ }^{37}$

12. En tercer lugar, resulta paradójico que en el núcleo de la cooperación más estrecha dentro del espacio europeo existe esta posibilidad de control, que sin embargo no existe en relación con los Estados con los que la vinculación es menos fuerte. Para las resoluciones (transacciones y documentos públicos, es claro) procedentes de Dinamarca en todo caso y para las de Gran Bretaña dictadas en procesos judiciales incoados antes del final del período transitorio ( 31 de diciembre de $2020^{38}$ ) se sigue el modelo de los arts. 23 ss. del reglamento, que no prevé nada del estilo. Pero si se trata de un crédito alimenticio no impugnado certificado como tal por las autoridades danesas al amparo del reglamento $805 / 2004$, este cauce será válido y tampoco habrá lugar a esta oposición, lo mismo que tampoco existe cuando se trate de decisiones a las que se aplique el convenio bilateral en materia de alimentos con Uruguay, los bilaterales de alcance general, el de La Haya sobre cobro de deudas de alimentos de 2007 o la LCJI.

13. Si la norma fuera clara los resultados en la jurisprudencia serían concurrentes. Pues bien, en España existen -salvo error tanto mío como de la base de datos- dos pronunciamientos que la manejan. Uno el que comento, otro el AAP de Huelva de 2 julio 2019: Si en aquel se interpretaba que había que aplicar cumulativamente el art. 518 LEC y las normas sobre prescripción de derechos (aunque recuérdese que todo pivota en torno al art. 1966.1 CC), en este se mantiene algo parecido a lo contrario, al aseverar que «...debe decirse que la prescripción que se alega del derecho a pedir alimentos, es una alegación de fondo que debería haberse hecho en el proceso declarativo en el Estado de origen, sin que sea de aplicación el art. 21.2 del Reglamento que invoca el recurrente, dado que se refiere a la prescripción de la acción para pedir la ejecución, lo que debe entenderse a la vista de la redacción del precepto, con la caducidad de la acción ejecutiva, que obviamente no concurre en este caso de reclamación de prestaciones periódicas como los alimentos de hijos menores, en las que el plazo no se cuenta desde la firmeza de la resolución que acuerda el devengo, sino desde que se devenga la cantidad reconocida ${ }^{39}$. Lo que hizo la Audiencia de Huelva fue fingir que el famoso art. 21 del reglamento no existe, limitando el razonamiento a lo que dispone la LEC española y sin la menor referencia al Derecho del Estado de origen. Justo lo contrario de lo que hace la de Lérida, aunque haya reclamado la toma en consideración de los plazos de fondo ${ }^{40} \mathrm{y}$ de los procesales ${ }^{41}$.

\footnotetext{
${ }^{36}$ No estamos en el declarativo, es claro. Todo tiene que desarrollarse con celeridad, y, en consecuencia, la aplicación de las reglas sobre anuncio de dictámenes y aportación posterior no se ajusta a las exigencias propias del trámite.

37 Piénsese además en la eventualidad de que el título extranjero no sea firme, que no sea ejecutivo en el Derecho del foro y que el tribunal de origen no haya uso de la facultad concedida en el art. 39 del reglamento para declarar su fuerza ejecutiva provisional: Desde luego, un incidente así contribuye bien poco a la promoción de los intereses del acreedor (no se puede extender las soluciones del sistema patrio a una resolución extranjera, porque no le se puede atribuir lo que no tienen de origen).

${ }_{38}$ Acuerdo sobre la retirada del Reino Unido de Gran Bretaña e Irlanda del Norte de la Unión Europea y de la Comunidad Europea de la Energía Atómica (2019/C 384 I/01), art. 67.

${ }_{39} \mathrm{~N}^{\mathrm{0}}$ 276/2019. La Audiencia descarta la aplicabilidad de las causas de oposición del art. 557 LEC entre las que se cita la prescripción o caducidad.

40 «...la normativa aplicable a efectos de prescripción no es el Código Civil de Cataluña sino el Código Civil, esto es, el Derecho común del Estado miembro de ejecución, lo que nos remite al plazo de prescripción de cinco años previsto en el art. 1.966-1 del CC».

${ }^{41}$ La batería de referencias y fechas del fundamento sexto está pensando exclusivamente en el día en el que se presentó la solicitud de ejecución en España de la sentencia polaca.
} 
14. Hay además en la resolución analizada tres detalles sobre los que quisiera llamar la atención:

a. Un déficit de congruencia: Dice el fundamento tercero que el deudor no ha planteado nada sobre eficacia del título ni sobre la cuantía. La puesta en funcionamiento de la norma queda a expensas de la formulación de oposición por el ejecutado, nunca de oficio, con lo que no se sabe cómo ha hecho la Audiencia para aplicar el CC. Pero es que, además, si alega la caducidad del título, no cabe estimar prescripción del derecho. El ejecutante impugna la oposición en base a unas alegaciones relativas al título en tanto que tal, y seguramente no dijo nada sobre el fondo: Su argumentación se tuvo que mover en el terreno de juego delimitado por la normativa procesal, no por las leyes sustantivas. Si esto no es indefensión...

b. Por supuesto que no se discute que, estimado el recurso, no se impongan las costas de la alzada a ninguna de las partes, mas la AP impone las de la primera instancia al ejecutado: Cabe preguntarse si a la luz de todo lo anterior no hay espacio para hablar de serias dudas de Derecho y consiguientemente no imposición en ningún caso: El tajante art. 561.1 LEC no puede ser entendido de forma tan rígida como expresa, porque se remite al 394, cuyo apartado 1 concede al tribunal una cierta capacidad de moderación, que podría haber usado (cuestión distinta es que el ejecutante se vea perjudicado por una norma deficiente).

c. ¿Cómo puede ser que la abogacía del Estado tarde tres años en solicitar del despacho de ejecución? Podremos estar de acuerdo en que se deben agotar las posibilidades de solución amistosa (art. 51 del reglamento), pero tres años sin actuar ante los tribunales parece que desborda los límites de la prudencia. Por consiguiente, es razonable afirmar que se abre la vía de la reclamación por la responsabilidad patrimonial de la administración, en los términos previstos en la ley 40/2015: La ley prevé una responsabilidad objetiva por daños y perjuicios antijurídicos, y resulta que: i) existe un daño efectivamente sufrido, real, evaluable económicamente e individualizable (art. 32), consistente en la diferencia entre lo que se tenía derecho a cobrar y lo que la entidad polaca de previsión haya abonado ${ }^{42}$; ii) la dilación ha sido la causa inmediata, directa y eficiente de los daños; iii) no consta que haya habido otra causa o factor que rompiera o interviniera en la relación de causalidad. No hay discrecionalidad. Existe una diferencia crucial en estos casos entre la actuación de un abogado y la de la autoridad central española (y por ende de la abogacía del Estado), porque mientras que en el primer caso existe un elemento de aleatoriedad (los resultados no están garantizados) y sólo es exigible que se comporte conforme a la lex artis, de manera que sólo es indemnizable «una disminución notable y cierta de las posibilidades de defensa de la parte suficientes para ser configuradas como una vulneración objetiva del derecho a la tutela judicial efectiva y por ello un daño resarcible en el marco de la responsabilidad contractual $»^{43}$, en el segundo la discrecionalidad judicial desaparece, al menos en la primera de las actuaciones exigibles, que es presentar la demanda ejecutiva. Es un acto debido, bien perfilado por el reglamento 4/2009, y su resultado no ofrece margen de duda (las expectativas de éxito son más que fundadas).

\section{Conclusión resignada}

15. Se puede descartar la idea de reconducir la norma del art. 21.2 del reglamento $4 / 2009$, interpretarla en clave de racionalidad, ajustarla a los demás principios inspiradores del sistema. Es demasiado contundente, y no deja opción sino para su aplicación estricta. Consecuentemente, cuando a un operador jurídico se le pida la ejecución de una resolución extranjera que condene al pago de una prestación de alimentos puede encontrarse con que el ejecutado formula como causa de oposición la extinción del de-

\footnotetext{
${ }^{42}$ La ley polaca de 7 de septiembre de 2007 sobre asistencia a personas que tienen derecho a percibir pensión alimenticia es bastante cicatera, estableciendo umbrales muy bajos para tener derecho a recibir prestaciones. Informaciones más detalladas aparecen en https://e-justice.europa.eu/content_maintenance_claims-47-pl-es.do?member=1\#toc_13

${ }^{43}$ La doctrina viene bien recogida en las SSTS 22 abril 2013 y 10 junio 2019, por ejemplo.
} 
recho a recibirlos, sea en el ordenamiento del Estado de origen de la resolución sea en el ordenamiento propio. La puesta en funcionamiento de la controvertida disposición pasa, en buena y ortodoxa lógica, por conocer qué dicen los ordenamientos en presencia, y a partir de la comparación llegar -en su caso- a declarar extinguido total o parcialmente el derecho a recibir pensión alguna. Se consigue así que lo que estaba disciplinado por el Derecho reclamado por la norma de conflicto (la del Protocolo de La Haya de 2007) pase a depender de las soluciones previstas en sistemas que no fueron los queridos por los legisladores que la elaboraron. $\mathrm{O}$ sea, que lo que el reglamento ha hecho ha sido modificar el art. 11 del Protocolo sin contar con norma habilitadora alguna. He aquí un ejemplo de incumplimiento de obligaciones internacionales, en definitiva. 